\title{
DEL GOCE LACANIANO A LA ESCRITURA FEMENINA: LA HISTERIZACIÓN DE LA PALABRA EN HÉLÈNE CIXOUS
}

\author{
MAIDER TORNOS URZAINKI \\ Universitat de Barcelona
}

\begin{abstract}
Históricamente, la mujer ha sido concebida exclusivamente como un ser enfermo. Desde el discurso científico-médico, la histeria sirve para descalificar el cuerpo femenino - su sexo, su goce-, cuya irreverencia pulsional resulta intolerable para la moral burguesa del sistema capitalista. El psicoanálisis lacaniano, si bien desprestigia el cuerpo femenino - siempre la mirada masculina sobre el cuerpo femenino en falta- su teoría va a suscitar mucho interés en los círculos feministas franceses. Reapropiándose de esa posición de 'no-toda', desde el afuera del sistema falo-logo/céntrico, la escritura femenina de los años 70 va a recurrir al goce suplementario teorizado por Lacan para demostrar la violencia que ejerce el discurso hegemónico.
\end{abstract}

PALABRAS CLAVE: Histeria, mujer 'no-toda', escritura femenina, goce suplementario.

From the Lacanian jouissance to the écriture féminine: Hysterization of the word in Hélène Cixous

Historically, within hegemonic thought, women have exclusively been conceived as diseased beings. From medical-scientific discourse, hysteria serves to discredit the female body -its sex, its jouissance-, whose irreverent drives become intolerable for the bourgeoise morality of the capitalist system. Even though Lacanian psychoanalytic theory relies on a masculine perspective that conceives of and discredits the female body as one at fault, it will generate a lot of interest in French feminist circles. Reappropriating the position of woman as 'not-all' and speaking from outside the phallo/logo-centric system, the écriture féminine of the '70s will use the supplementary jouissance theorized by Lacan to make evident the violence that is practiced by hegemonic discourse.

KEY WORDS: Hysteria, woman as 'not-all', écriture féminine, supplementary jouissance.

Sur les planchers du pont, sur les parvis du bateau, sur la mer, avec le parcours du soleil dans le ciel et celui du bateau, se dessine, se dessine et se détruit à la même lenteur, une écriture, illisible et déchirante d'ombres, d'arêtes, de traits de lumière 
brisée reprise dans les angles, les triangles d'une géométrie fugitive qui s'écoule au gré de l'ombre des vagues de la mer. Pour ensuite, de nouveau, inlassablement, encore exister.

-MARguerite Duras, L'amant de la Chine du Nord

La sociedad capitalista — con el fin de proteger el sistema social— trata de limitar la violencia destructiva que emana de la dimensión de lo real-pulsional, adaptando las estructuras lingüísticas al orden socio-económico y sometiendo el lenguaje a las normas de una gramaticalidad estricta. La estrategia consiste en acomodar el goce a las estructuras simbólicas del discurso, para arrebatar al texto toda su capacidad revolucionaria, restringiendo el lenguaje a una función meramente comunicativa, tal y como exige el sistema de valores de la sociedad capitalista. En este contexto, más allá de la lógica económica que impone el capitalismo, la experiencia de la histeria ofrece nuevas posibilidades al lenguaje, ya que tiene la capacidad de cuestionar la univocidad del signo lingüístico saussureano, al permitir que la violencia irracional que emana de lo real del cuerpo desestructure la dimensión del lenguaje. La teatralidad del cuerpo femenino - histérico y convulso - arremete con fuerza contra todo orden establecido, al introducir el movimiento pulsional en la palabra y corporeizar la letra con la exuberancia del goce, destruyendo los límites que impone el lenguaje racional y discursivo. Por eso, en los años 70, la escritura femenina de Hélène Cixous recupera la carga pulsional que atraviesa el cuerpo histérico (y su palabra), con el fin de cuestionar el monolingüismo del discurso falologo/céntrico, que funciona a partir de la violencia y la exclusión de aquello que no puede tener un nombre. A través de la desestabilización del campo simbólico - consecuencia de la transgresión de la ley fálica- la escritura femenina se acerca a los abismos del lenguaje y, más allá de los límites de lo conocido (desde la ignorancia que sacude el saber), revela la capacidad política de una palabra irreverente y llena de goce, que se escribe con el cuerpo. Así, en el momento en que la histeria, la violencia pulsional y el sexo invaden y destruyen la palabra, la escritura femenina se convierte en el espacio que negocia, constantemente, la lógica (¿económica?) del sistema falo-logo/céntrico, recuperando la exterioridad de lo femenino, como aparato deconstructivo del discurso hegemónico.

\section{Asentando las bases del cuerpo sintomático}

Comme dans le cas de la petite fille assise, il y a un conflit initial entre le désir et son interdiction, mais cette fois violent comme la crise de puberté en cause. Insoluble, ce conflit ne peut conduire qu'au refoulement du sexe, à sa projection sur l'œil, l'oreille, et le nez: projection ou déplacement qui 
nous explique - à la base même du phénomène - la valorisation hyperbolique des organes des sens, la dramatisation de leurs fonctions.

La histeria, explican Plon y Roudinesco, "est une névrose caractérisée par des tableaux cliniques variés. Son originalité réside dans le fait que les conflits psychiques inconscients s'y expriment de manière théâtrale et sous la forme de symbolisations, à travers des symptômes corporels paroxystiques (attaques ou convulsions d'allure épileptique) ou durables (paralysies, contractures, cécité)"

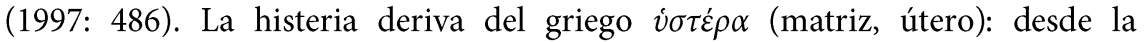
antigüedad -concretamente, con Hipócrates-, hace referencia a una enfermedad orgánica de origen uterino, asociada con el cuerpo de la mujer. Posteriormente, dicen Plon y Roudinesco, "[d]ans son Timée, Platon reprit la thèse hippocratique en soulignant que la femme, à la différence de l'homme, portait en son sein un 'animal sans âme'. Proche de l'animalité: tel fut pendant des siècles le destin de la femme, et plus encore de la femme hystérique" (1997: 487). De esta manera, la histeria sirve para descalificar el cuerpo femenino: un cuerpo que, al ser identificado con la violencia pulsional de la animalidad, sólo puede ser castigado. En la Edad Media, en las concepciones agustinianas, la histeria deja de pertenecer al ámbito específico de la medicina, para integrar el catálogo de perversiones de la Iglesia Católica, ya que considera que el cuerpo de la histérica -espasmódico y teatralizado- está poseído por el demonio y, como tal, debe ser condenado. ${ }^{1}$ En el siglo XVIII, Franz Anton Mesmer reintroduce la histeria - nuevamente- en el ámbito médico y, con la revolución de Pinel, se pone fin a la teoría de la demonología en beneficio de una concepción psiquiátrica de la enfermedad mental, que incluye la histeria como una enfermedad de los nervios, producto del desequilibrio homeostático del fluido corporal. A finales del siglo XIX, el problema de la histeria pasa a un primer plano en el pensamiento médico y anatomoclínico, pero la manera de concebir y enfrentarse a la enfermedad marca el trabajo de dos escuelas diferentes: por una parte, está la hipótesis defendida y desarrollada por Babinski que - al comprobar la ausencia de lesión orgánica - atribuye los síntomas histéricos a la autogestión o la simulación; y, por otra parte, está la escuela de la Salpêtrière -con Charcot- que libera a las mujeres histéricas de la sospecha de la simulación y concibe la histeria como una enfermedad tan definida y precisa como una afección neurológica. Años más tarde, en 1895, Breuer y Freud publican Estudios sobre la histeria, considerado el libro inaugural de la ciencia psicoanalítica, en donde tratan de superar la oposición entre las dos escuelas: influenciados por la perspectiva de la Salpêtrière, ambos llegan a la conclusión de que la histeria es

\footnotetext{
${ }^{1}$ Como ejemplo, la figura de la bruja, recuperada de manera positiva por Jules Michelet, en $L a$ bruja. Un estudio de las supersticiones en la Edad Media (1987).
} 
una enfermedad psíquica con una etiología específica, pero también recuperan las enseñanzas de Babinski y se adhieren a esa corriente de pensamiento que considera la histeria como una enfermedad por representación, con lo que elaboran la teoría de la seducción y, posteriormente, la teoría imaginaria del fantasma. ${ }^{2}$ Finalmente, en la Interpretación de los sueños (1900), Freud afirma que la histeria emerge a causa de un conflicto físico inconsciente no resuelto, que motiva la creación de un segundo cuerpo mortífero (y lleno de goce) que - plegado a las exigencias dramáticas del síntoma- destruye la anatomía. De este modo, la histeria configura un laberinto de carne - el cuerpo dentro del cuerpo- que se vive desde la subjetividad del síntoma, como desafío a la estructura anatómica del cuerpo y la biología. Así, dice Assoun, "le défi de l'hystérique: faire $d u$ corps avec son symptôme" (1997: 24, cursiva en el original). La histeria, por lo tanto, construye el cuerpo desde el síntoma, atravesando los pliegues de la anatomía, para dar la bienvenida al acontecimiento de la carne (y del goce). Así, desde un cuerpo roto por las pulsiones irrefrenables y las convulsiones nerviosas, la histeria se convierte en una invitación a la desobediencia, en contra de las restricciones que el sistema capitalista impone sobre el cuerpo. El goce de la histeria - frenético e inadaptado- se cuela entre los puntos de sutura y, con el fluir de lo femenino, cuestiona el sistema sociopolítico que sustenta el mundo capitalista, destruyendo - a su paso- los convencionalismos que restringen el lenguaje racional y discursivo. Por eso, como la violencia del goce histérico choca con los parámetros delimitados por la moral económica del sistema capitalista, la ciencia médica y la psiquiatría trabajan para silenciar la experiencia histérica $y$, por ese motivo, patologizan el cuerpo femenino que está lleno de goce, porque su intención es preservar la homeostasis del sistema social. De esta manera, los mecanismos terapéuticos revelan su constitución política, demostrando que la enfermedad es una construcción cultural, en donde los métodos curativos nunca son inocentes. Al fin y al cabo, si la histeria fuera 'sólo' una cuestión patológica nunca se habría

\footnotetext{
${ }^{2}$ Según explican Roudinesco y Plon, en Dictionnaire de la Psychanalyse: "Le mot séduction renvoie d'abord à l'idée d'une scène sexuelle où un sujet, généralement adulte, use de son pouvoir réel ou imaginaire pour abuser d'un autre sujet, réduit à une position passive: un enfant ou une femme en général. [...] C'est bien de cette représentation de la contrainte que part Freud quand il construit, entre 1895 et 1897, sa théorie de la séduction selon laquelle la névrose aurait pour origine un abus sexuel réel. [...] En écoutant des femmes hystériques de la fin du siècle lui confier de telles histoires, Freud se satisfait de l'évidence de leurs discours et bâtit sa première hypothèse du refoulement et de la causalité sexuelle de l'hystérie sur la théorie de la séduction. Il pense que c'est parce qu'elles ont réellement été séduites que ces femmes hystériques sont atteintes de troubles névrotiques" (1997: 982). A partir de 1897, Freud abandona la hipótesis sobre la seducción e introduce la teoría sobre el fantasma, en donde ya no interesa el alcance real de la historia de los abusos sexuales (o no tanto), sino su dimensión imaginaria.
} 
reducido su tratamiento al matrimonio de las mujeres viudas o solteras, ${ }^{3}$ tratando de aliviar el dolor de una (supuesta) enfermedad a través de una serie de mecanismos ajenos al procedimiento médico y psiquiátrico. Así, a través de la experiencia de la histeria, la mujer entra - por primera vez - en el discurso hegemónico, pero lo hace como una enferma, para condenar un goce femenino y desautorizado, que queda al margen de las restricciones que impone la lógica económica del sistema capitalista.

\title{
El goce suplementario de la mujer
}

\author{
Eh! ¿Qué es eso? Exo. ¿Sabes qué es eso? \\ eso, exo, eso es un sexo. ¿Sabes qué es? eso \\ exo es, sexo es, este exceso. El sexo fue el \\ primer exceso; causó y causa todos los \\ excesos... ¿Qué tengo? ¿qué tengo? quequé \\ tengo. ¿Qué tengo que es? quequé es esto. \\ ¿Qué que eres? Quéquete. ¿Qué quieres tú? \\ quéque quieres. ¿Qué tengo que es esto que \\ tengo en? ¿Qué tengo que sexo tengo tiene? \\ ¿quesquesex?" \\ -JEAN-PIERRE BRISSET, Diccionario abreviado del \\ surrealismo
}

A lo largo de los años, Lacan trata de responder a la pregunta ‘qué quiere una mujer?' que Freud había dejado sin resolver y, por ese motivo, se interesa por el cuerpo de la mujer y, concretamente, por el goce femenino de la mujer histérica. De hecho, este interés queda reflejado - de manera temprana- en su tesis doctoral, dedicada a analizar la figura de Marguerite Anzieu: una moderna Emma Bovary. Posteriormente, en el seminario de Encore (1972-1973), Lacan sustentado en la hipótesis freudiana sobre la fase fálica- elabora la teoría del proceso de sexuación $y$, a partir de ese momento, el goce aparece ligado a la identidad sexual, estableciendo la diferencia entre el goce fálico y el goce femenino (o suplementario), que tiene la capacidad de transgredir el orden simbólico del lenguaje, en donde se revela la fuerza poética de una palabra que queda más allá de los límites racionales del discurso. A partir de aquí, Lacan comprende que la histeria es una experiencia que afecta a la estructura simbólica del lenguaje, porque el cuerpo histérico - transido de goce y violencia - se rebela en contra del proceso de sexuación que impone el significante fálico, incapaz de aceptar la violencia simbólica que instituye el Nombre-del-Padre. De esta manera, más allá de la autoridad paterna, la violencia pulsional del cuerpo

\footnotetext{
${ }^{3}$ En la antigüedad, según explica Roudinesco, "le traitement [de l’hystérie] recommande le mariage pour les jeunes filles et le remariage pour les veuves" (1994a: 44).
} 
histérico descubre una dimensión extraña y desconocida: es 'el-otro-lado' del orden simbólico del lenguaje; ese suplemento de goce (femenino) que excede la racionalidad discursiva, en donde ya sólo habla la sombra y el silencio.

En "Tres ensayos sobre teoría sexual" (1905), Freud analiza de manera pormenorizada la sexualidad humana y, a partir del modelo de la biología darwinista, propone la teoría del monismo sexual, en donde la libido es de esencia masculina. Unos años después, en "La organización genital infantil (una interpretación en la teoría de la sexualidad)" (1923), Freud afirma que la sexualidad infantil se construye a partir del par antitético fálico/castrado - de acuerdo con una fase fálica, en donde sólo se reconoce el órgano genital del hombre $-{ }^{4}$ y llega a la conclusión de que la oposición masculino/femenino aparece posteriormente, con el desarrollo de la pubertad. ${ }^{5}$ Así, según explica Freud, el hecho de que la sexualidad se construya en relación a la marca sexual masculina - desde la posición dicotómica de fálico/castrado- origina distintas maneras de enfrentarse con el complejo de Edipo, no sólo por las diferencias anatómicas, sino sobre todo por las fantasías que suscitan estas diferencias: en el niño, el miedo a la castración; en la niña, la envidia del pene. A partir de aquí, Freud afirma que "lo masculino reunirá el sujeto, la actividad y la posesión del pene, lo femenino perpetuará el objeto, la pasividad y [...] el órgano genital

\footnotetext{
${ }^{4}$ La significación de la fase fálica, especialmente en la niña, ha dado lugar a muchas discusiones. Autores como Karen Horney, Melanie Klein o Ernst Jones hablan de un conocimiento intuitivo y primario de la cavidad vaginal y se ven inducidos a considerar la fase fálica sólo como una formación secundaria de tipo defensivo. No creen, por lo tanto, que la niña 'ignore' la vagina (y la sustituya por el clítoris), sino que consideran que la niña 'deniega' la vagina.

En la misma línea, Irigaray afirma lo siguiente: "Esa denegación de la vagina por parte de la chiquilla se justificaría por el hecho de que es, a su vez, temido. La comparación del pene de un hombre adulto con la exigüidad de la vagina infantil, la visión de las menstruaciones, o incluso eventuales y dolorosos desgarros del himen durante las exploraciones manuales han podido, en efecto, instigar en la chiquilla el temor a tener una vagina, y a negar lo que ella sabe de su existencia" (2009: 23).

${ }^{5}$ Para muchos psicoanalistas, la fase fálica de la teoría freudiana proporciona el retorno a la androginia -que permite superar el horror que provoca el corte de los dos sexos, a través de la indiferenciación de las marcas sexuales-, ya que el juego no se sostiene en la dualidad masculino/femenino, sino en la dualidad fálico/castrado. En este sentido, por ejemplo, Brown comenta: "la diferenciación sexual de la libido adulta [...] es una pérdida de la integridad sexual. Por eso, el hecho de la diferenciación sexual se mira con horror. En cada sexo, dice Freud, hay la actitud que pertenece al sexo opuesto que sucumbe a la represión. En cada sexo el inconsciente no acepta la represión sino que quiere recuperar la bisexualidad de la infancia. [...] En el nivel más profundo el ideal andrógino o hermafrodita del inconsciente refleja la aspiración del cuerpo humano de superar los dualismos que son sus neurosis" (1959: 153). Sin embargo, no parece acertado identificar la androginia con la fase fálica de la teoría freudiana, porque la marca femenina del cuerpo sexuado no es reconocida en ningún momento, sólo el órgano genital masculino.
} 
castrado" (2003: 149). En este sentido, de acuerdo con la teoría freudiana, el cuerpo de la mujer - privado de determinación ontológica- es un recipiente que contiene las proyecciones del otro sexo: el único cuerpo sexuado. La mujer - su cuerpo, su sexo- es el reverso negativo, el lugar de la falta, la topología de la envidia, que sirve únicamente para que el sexo masculino encuentre la autorrepresentación de su propio cuerpo.

En Encore (1972-1973), a partir de la dicotomía freudiana de la fase fálica, Lacan plantea la teoría de un goce femenino suplementario, que supera los límites establecidos por el goce fálico de la dimensión simbólica. Así, sustentado en la teoría freudiana, Lacan explica que la envidia del pene y la angustia de castración motivan la creación del falo: un registro imaginario que, frente a la carencia del objeto real que estructura la diferencia, permite recubrir la falta. Por lo tanto, desde la dimensión imaginaria, el falo se convierte en el significante simbólico que - con la ayuda del Nombre-del-Padre- ordena el juego dialéctico del complejo de Edipo y, además, codifica el registro del deseo. Así, como consecuencia de esta teoría sobre la sexualidad, Lacan postula que el goce suplementario de la mujer se sitúa más allá del significante fálico $y$, concretamente, en un cuerpo sintomático que posibilita la implicación del goce en la dimensión del gran Otro, al rechazar la ley de la castración impuesta por el Nombre-del-Padre y, por lo tanto, exceder el orden simbólico del lenguaje. Influenciado por el complejo de Edipo - por ese momento concreto en el que el niño y la niña comparan sus cuerpos- Lacan llega a la conclusión de que el traumatismo ocasionado por la ausencia de pene obliga a la mujer a enfrentarse con su ser incompleto y siempre en falta: "Il n'y a pas $L a$ femme, article défini pour désigner l'universel. Il n'y a pas $L a$ femme puisque [...] de son essence, elle n'est pas toute", dice Lacan (1999: 93). La mujer está marcada por el signo de la carencia; la ausencia de pene la sitúa en una posición inferior y disminuida - en un vacío que no puede llegar a simbolizar-, porque la mujer 'no-toda' es. Y en ese momento preciso, explica Lacan, desde esa posición siempre en falta, surge el goce suplementario de la mujer:

Il n'en reste pas moins que si elle est exclue par la nature des choses, c'est justement de ceci que, d'être pas toute, elle a, par rapport à ce que désigne de jouissance de la fonction phallique, une jouissance supplémentaire. [...] Ce n'est pas parce qu'elle est pas-toute dans la fonction phallique qu'elle y est pas du tout. Elle y est pas pas du tout. Elle y est à plein. Mais il y a quelque chose en plus. [...] Il y a une jouissance [...] au-delà du phallus. [...] Il y a une jouissance à elle, à cette elle qui n'existe pas et ne signifie rien. Il y a une jouissance à elle dont peut-être elle-même ne sait rien, sinon qu'elle l'éprouve - ça, elle le sait. (Lacan, 1999: 94-95, cursiva en el original) 
El 'no-toda' que define el ser de la mujer no puede quedar simbolizado en la dimensión del lenguaje, porque la estrategia femenina no consiste en acogerse al consuelo que proporciona la dimensión del falo imaginario -como compensación por la falta que atraviesa su cuerpo-, sino que consiste en rebelarse contra el corte que imprime la castración simbólica, a través de un goce suplementario que permite impugnar la falta. Así, según el psicoanálisis lacaniano, si bien la mujer está marcada por una carencia real - ya que le falta el órgano genital masculino-, el hecho de sustraerse al control que ejerce el significante fálico hace que la mujer acceda a ese goce suplementario, en donde "elle y est à plein" (Lacan, 1999: 95). Por eso, para Lacan, la mujer no puede decir su propio goce, porque queda más allá de la omnipotencia del significante fálico, como un resto imposible que transgrede el orden simbólico del lenguaje: ese es el acto de desobediencia de la mujer, en contra del binarismo sexual que impone la ley de la castración simbólica del lenguaje, en donde la mujer — signo de un 'goce Otro'- queda reducida a ocupar el segundo término de la jerarquía, de acuerdo con la dialéctica hegeliana del amo y del esclavo. De esta manera, Lacan anuncia la incompletud del cuerpo femenino, en donde emerge la posibilidad de un goce suplementario - más allá del lenguaje racional y discursivo-, cuando la mujer consigue transgredir la ley de la castración simbólica que impone el significante fálico del Nombre-del-Padre. Sin embargo, dice Miller, la teoría sobre el goce femenino también sustenta "la espantosa explicación, el pesado lugar común que hace de la mujer el ser inferior [...] el principio de la degradación del ser femenino" (2008: 281).

\title{
La llegada de la risa, la llegada de la escritura
}

\author{
Ser tartamudo del lenguaje, extranjero de \\ la propia lengua. \\ -GILLES DELEUZE y FÉLIX GUATTARI, \\ Mil mesetas: capitalismo y esquizofrenia
}

En los años 70, desde las bases del feminismo francés, el cuerpo de la mujer histérica va a ser recuperado rechazando el discurso de las ciencias médicas, cuya finalidad (o, por lo menos, una de ellas) es patologizar el cuerpo para silenciar el goce, con el fin de mantener intactas las estructuras socio-económicas del sistema capitalista. En estos momentos, aparecen las obras Le Corps lesbien (1973) de Monique Wittig, Speculum de l'autre femme (1974) de Luce Irigaray, La révolution du langage poétique (1974) de Julia Kristeva y Le Rire de la Méduse (1975) de Hélène Cixous - textos marcadamente políticos- que contribuyen a la consolidación de los estudios femeninos en Francia. Sin embargo, el feminismo francés de los años 70 no va a desechar la conceptualización teórica del discurso científico, sino que va a reivindicar ese cuerpo histérico, como lugar 
preciso desde donde volver a retomar la palabra, otorgando la voz al cuerpo y al goce. De esta manera, al invertir la negatividad del discurso lacaniano, el feminismo va a aceptar la siguiente consigna: "[la femme] il y a toujours quelque chose qui chez elle échappe au discours" (Lacan, 1999: 45) y, a través de esa consigna, el feminismo francés combate la hegemonía del discurso falologo/céntrico, que funciona según esquemas domésticos a partir de la exclusión y el rechazo. En este sentido, frente a la estigmatización de la mujer por parte del psicoanálisis lacaniano, la teoría feminista se sitúa en la posición del rechazo, para reivindicar un discurso propio, hecho con los jirones de un cuerpo fragmentado y lleno de goce, que no se doblega frente a las exigencias del sistema capitalista. ${ }^{6}$ Así, el feminismo francés se apropia de ese 'no-toda' lacaniano que atraviesa a la mujer histérica y, desde esa incompletud, escribe (mujer) haciendo hueco al cuerpo, al dolor y al goce. Por lo tanto, la mujer ocupa una posición excéntrica: es lo que queda fuera, lo que no es representable en el ámbito de la metafísica, en definitiva, lo que (como su sexo) está ausente. Por eso, porque la mujer es irrepresentable en el sistema logocéntrico, el feminismo debe abandonar el pensamiento filosófico, para acercarse a la verdad que se manifiesta en la catacresis $^{7}$ del discurso. Al fin y al cabo, explica Cixous, en el pensamiento filosófico

[t]out revient à l'homme, à son tournement à lui, son désir d'être (à) l'origine. Au père. Il y a un lien intrinsèque entre le philosophique - et le littéraire (dans la mesure où elle signifie, la littérature est commandé par le philosophique) - et le phallocentrisme. Le philosophique se construit à partir de l'abaissement de la femme. Subordination du féminin à l'ordre masculin qui apparaît comme la condition du fonctionnement de la machine. (Cixous, 2010b: 74-75)

\footnotetext{
${ }^{6}$ Según explica Collin, el feminismo tiende a apropiarse de la descalificación con el fin de desactivar el insulto y construir un nuevo espacio político de lucha: "Como el 'black is beautiful' del movimiento negro americano, 'female is beautiful' será uno de los eslóganes de esta tendencia. Se trata de convertir una calificación negativa en una cualidad positiva, de enorgullecerse y honrarse de lo que se ha denigrado injustamente durante siglos, exaltando la diferencia en vez de intentar superarla, haciendo de ella una fuente generadora del campo simbólico. Así, la creación de las mujeres recurrirá con frecuencia a los caracteres atribuidos a la femninidad tradicional para despojarlos de su indicio negativo, positivarlos y reivindicarlos: el no-uno, la fluidez, la porosidad, la plasticidad, la sensualidad generalizada, la particularidad, la dispersión temporal" (2006: 175).

${ }^{7}$ Butler define la catacresis del siguiente modo: "those figures that function improperly, as an improper transfer of sense, the use of a proper name to describe that which does not properly belong to it, and that return to haunt and coopt the very language from which the feminine is excluded" (1993: 37).
} 
El hombre es el 'ser-todo', representa la omnipotencia de la completud en donde se sostiene la unidad totalizadora del discurso falo-logo/céntrico, que funciona en la exclusión de lo femenino. Sin embargo, en estos momentos, la finalidad del feminismo no es ocupar el espacio del Hombre, sino deconstruir su espacio; colocarse en el 'afuera' —en la huella borrada del discurso-, para desmontar la lógica del pensamiento hegemónico. Al margen del discurso pasivo y victimista de la envidia freudo-lacaniana, la teoría feminista repolitiza el espacio del afuera, como un lugar plural de resistencia. De esta manera, a partir de una estrategia performativa, la finalidad es convertir la exterioridad en una mirada crítica que - de un modo insistente - cuestione los límites internos que circunscriben el sistema falo-logo/céntrico.

En Le Rire de la Méduse (1975), Cixous habla de la escritura femenina y, al invertir la conceptualización lacaniana sobre la incompletud de la mujer, recupera el goce suplementario de la experiencia histérica, porque considera que la violencia pulsional que emerge de lo real del cuerpo puede desestructurar el orden simbólico del lenguaje, cuestionando la hegemonía del discurso falologo/céntrico. Así, comenta Cixous, "Je parlerai de l'écriture féminine: de ce qu'elle fera. Il faut que la femme s'écrive: que la femme écrive de la femme et fasse venir les femmes à l'écriture, dont elles ont été éloignées aussi violemment qu'elles l'ont été de leurs corps" (2010a: 37, cursiva en el original). ${ }^{8}$ Cixous concibe una escritura marcada por la(s) diferencia(s), en donde la mujer — de acuerdo con el apelativo freudiano- se equipara con el continente africano, ${ }^{9}$ metáfora de la exterioridad que — algún día, con la risa de la Medusaconseguirá desestructurar la homogeneidad y el monolingüismo del discurso hegemónico. De esta manera, si bien el pensamiento falo-logo/céntrico aleja a las mujeres del discurso y las reduce a los entresijos del cuerpo, Cixous invierte el castigo y se apropia del lugar asignado como condena, para sustentar el nacimiento de una escritura femenina e histérica: "plus corps donc plus écriture", dice Cixous (2010a: 57). Por lo tanto, la mujer recupera la voz y, a través de la teatralidad de la palabra (reminiscencias del cuerpo histérico), introduce un surplus de goce que consigue cuestionar el pensamiento hegemónico y su violencia, apelando a una exterioridad que no puede quedar contenida en los límites que circunscribe el lenguaje racional y discursivo. En este sentido, al reivindicar la experiencia histérica y la categoría de lo femenino, Cixous escribe la diferencia, pero para convertirla en el universal que soporta el cuestionamiento

\footnotetext{
${ }^{8}$ Y sigue, en otro fragmento: “Et pourquoi n'écris-tu pas? Écris! L'écriture est pour toi, tu es pour toi, ton corps est à toi, prends-le. Je sais pourquoi tu n'as pas écrit. (Et pourquoi je n'ai pas écrit avant l'âge de vingt-sept ans). Parce que l'écriture c'est à la fois le trop haut, le trop grand pour toi, c'est réservé aux grands, c'est-à-dire aux 'grands hommes'; c'est de 'la bêtise"' (Cixous, 2010a: 39).

${ }^{9}$ Freud habla de la mujer como un continente africano, por primera vez, en el texto “¿Pueden los legos ejercer el psicoanálisis? Diálogos con un juez imparcial” (1926).
} 
crítico del discurso logocéntrico $;^{10}$ lo femenino se convierte, entonces, en la estrategia política de la deconstrucción. Por eso, dice Cixous, "[l]es vrais textes de femmes, des textes avec des sexes de femmes, ça ne leur fait pas plaisir; ça leur fait peur; [...] un texte féminin ne peut pas ne pas être plus que subversif" (2010a: 40 y 59).

Desde la exterioridad del pensamiento, consciente de su posición crítica, Cixous escribe abriendo el discurso falo-logo/céntrico a lo que escapa de él y lo transgrede, pero no para garantizar la completud del sistema, sino para revelar la disrupción interna que recorre y atraviesa todo signo identitario. Ahora, para Cixous, la apertura hacia lo desconocido no puede narrarse a partir de un sistema logocéntrico que no hace más que reforzar la soberanía de la unidad, a través de un proceso de asimilación en donde la diferencia queda eliminada o, por lo menos, escondida bajo la uniformidad que impone el sistema. Por eso, frente a la violencia que ejerce el discurso falo-logo/céntrico, Cixous busca un nuevo lenguaje que sea capaz de conservar lo desconocido; un lenguaje femenino (e histérico) que se abra a la exterioridad que escapa a la conceptualización discursiva, para acoger la alteridad que queda fuera de los límites internos establecidos por el sistema. Así, dice Cixous,

[j]e crois que quand j'écris, c'est parce que quelque chose va de l'une à l'autre, aller et retour. Mais aussi, pour jouer, j'ai écrit: de lune à l'autre. C'est un jeu mais sérieux. C'est une façon de déhiérarchiser - tout. Nous, qui sommes géocentriques, comme nous sommes anthropocentriques, nous disons: de la terre à. Et la lune, c'est l'autre. Il $\mathrm{y}$ a très longtemps que je me sens dans un rapport poétique et fantasmatique, à la lune notre autre... à qui je dis toujours - muettement en la regardant - excuse-moi de faire comme si c'était toi l'autre, alors que c'est toi lune. Changeons. Si j'écris "de lune à l'autre", à ce moment là, l'autre ce serait la terre. Et c'est une bonne chose. Chacune chacun son tour. De toutes les manières. Pas seulement parce qu'il faut faire valser les hiérarchies; c'est aussi parce que, à force d'ordonner sans le savoir, c'est-à-dire d'être ordonnés d'avance par la langue, on prive tout le monde de tout. Nous nous privons nous-mêmes

${ }^{10}$ De hecho, para Cixous, la escritura femenina no es específica de la mujer, sino de lo femenino, como marca universal que soporta el diferir del discurso logocéntrico. Dice Cixous: "Et quand il s'écrit un semblable déferlement depuis un corps d'homme, c'est qu'en lui la féminité n'est pas interdite. Qu'il ne fantasme pas sa sexualité autour d'un robinet. Il n'a pas peur de manquer d'eau, il ne s'arme pas de son bâton mosaïque pour battre le rocher. Il dit: 'J'ai soif, et l'écriture jaillit. Sombrer dans sa propre nuit, être en rapport avec ce qui sort de mon corps comme avec la mer, accepter l'angoisse de la submersion. Faire corps avec le fleuve jusqu'aux rapides plutôt qu'avec la barque, s'exposer à ce danger, c'est une jouissance féminine" (Cixous, 1986: 68 y 69). 
de l'altérité - de l'altérité de la terre. Nous-mêmes, nous finissons par ne plus la voir d'un autre point de vue, alors qu'elle en a absolument besoin. La terre vue du point de vue de la lune est ranimée: elle est inconnue; elle est à retrouver. (Cixous, 1994: 20, cursiva en el original)

La escritura histérica de Cixous - suspendida en esa exterioridad silenciosa, al cuestionar la autoridad del significante fálico - se abandona a la deriva y el desplazamiento, para dar la bienvenida a la alteridad irrepresentable que descentra el discurso hegemónico, cuestionando los límites internos que sustentan la metafísica de la propiedad y el sentido del sistema falo-logo/céntrico. Sin embargo, su finalidad no es apropiarse de la alteridad, sino señalar su presencia, en el hueco vacío que deja siempre su ausencia. Así, comenta Cixous, “[j]'ai peut-être écrit pour voir; pour voir ce que je n'aurais jamais eu; pour qu'avoir ne soit pas le privilège de la main qui prend et enferme; du gosier, de l'estomac. Mais de la main qui montre du doigt, des doigts qui voient, qui dessinent, du bout des doigts qui tracent sous la douce dictée de la vision" (1986: 12). Desde el límite, a través de un cuerpo histérico que no se pliega a los designios del orden simbólico del lenguaje, Cixous trata de señalar el vacío que revela la alteridad, para destruir la totalidad y el monolingüismo de la lógica discursiva. Sin ninguna intención de poseer aquello que se escapa, para llegar a ser completo, la escritura femenina espacia el espacio, "pour saturer de désir la distance" (Cixous, 1986: 12). De esta manera, al incidir en la distancia - para impedir la posesión-, Cixous no colma el abismo, sino que ahonda en el espacio de la diferencia, creando una escritura bisexual que - sin ocultar lo femenino en la omnipotencia del significante fálico- es capaz de acoger diferentes marcas sexuales al mismo tiempo. En este sentido, afirma Cixous,

[é]crire c'est justement travailler (dans) l'entre, interroger le procès du même et de l'autre sans lequel rien ne vit, défaire le travail de la mort, c'est d'abord vouloir le deux, et les deux, l'ensemble de l'un et l'autre non pas figés dans des séquences de lutte et d'expulsion ou autre mise à mort, mais dynamisés à l'infini par un incessant échangement de l'un entre l'autre sujet différent, ne se connaissant et se recommençant quà partir du bord vivant de l'autre: parcours multiple et inépuisable à milliers de rencontres et transformations du même dans l'autre et dans l'entre, d'où la femme prend ses formes. (Cixous, 2010a: 51-52)

Para permanecer en el espacio del 'entre' - en ese intersticio que escribe expandiendo la distancia- Cixous crea un significante que, más allá de la autorreferencialidad del signo lingüístico, se abandona al exceso an-económico del goce y permanece en suspenso. Al destruir el sistema de equivalencias, la posición del sentido que representa el significado deja de ser el final teleológico donde descansa el significante $y$, de esta manera, el lenguaje se abre a la polisemia 
y se convierte en devenir y trayectoria, destruyendo la homeostasis económica del lenguaje racional y discursivo. Ahora, a través del componente afectivo que destruye la univocidad del signo lingüístico, la escritura femenina trata de romper con el discurso hegemónico y, al incidir en la distancia que separa el significante y el significado, introduce el deseo en la palabra: el deseo de clausurar el signo, detener el movimiento y agotar el significado. Sin embargo, la palabra de Cixous - siempre a la espera - se presenta en forma de pregunta sin respuesta: es una palabra que no afirma nada, sólo cuestiona, para acoger —en la incertidumbre- el silencio de aquello que quedó sin nombre. Por eso, comenta Cixous,

[j]'étais ce désir. J'étais la question. Etrangeté du destin de la question: chercher, poursuivre les réponses qui la calment, qui l'annulent. Ce qui l'anime, la lève, lui donne envie de se poser, c'est l'impression que l'autre est là, si proche, existe, si loin, qu'il y a, quelque part, au monde, une fois passée la porte, la face qui promet, la réponse pour laquelle on continue à se mouvoir, à cause de laquelle on ne peut se reposer, pour l'amour de laquelle on ne retient de renoncer, de se laisser aller; à mourir. Quel malheur pourtant, s'il arrivait à la question de rencontrer sa réponse! Sa fin! (Cixous, 1986: 9-10)

La imposibilidad de cerrarse sobre sí mismo hace que el lenguaje permanezca suspendido, en el extremo del límite que marca el sistema, a la espera de una respuesta que nunca llega. Y es precisamente esa imposibilidad, que no debe ser entendida como carencia, la que permite que el lenguaje escape a la violencia de la identidad que impone el sistema falo-logo/céntrico. Ahora, ya sólo se oye el eco de la pregunta - que no hace más que reafirmar la pregunta sin respuesta-, haciendo que cada palabra se ponga a la escucha de una alteridad irreductible que excede el sistema. De este modo, la escritura histérica y bisexual de Cixous permite destruir la autocomplacencia del sistema logocéntrico, al ponerlo en contacto con una exterioridad que supera los marcos internos del sistema, profanando cada palabra con la fuerza de lo extranjero. Según dice Cixous, "[d]ans ma langue ce sont les langues 'étrangères' qui sont mes sources, mes émois. 'Étrangères': musique en moi d'ailleurs; précieux avertissement: n'oublie pas que tout n'est pas ici, réjouis-toi de n'être qu'une parcelle, une graine de hasard, il n'y a pas de centre du monde, lève-toi, vis l'innombrable, écoute l'intraduisible; souviens-toi que tout est là" (1986: 31). La escritura femenina, por lo tanto, plantea una experiencia no dialéctica de la palabra; es una escritura que habla sin igualar, sin identificar, para acoger la presencia del extranjero, en la deconstrucción de los límites internos del sistema falologo/céntrico.

Así, la escritura femenina desestructura la lengua dominante, al abrirse a lo desconocido, enfrentando la palabra con el silencio. En estos momentos, la 
irreverencia del goce histérico (y femenino) rompe con la violencia del sistema dominante, haciendo - como dice Blanchot (1969) - que la interrupción se haga sentido y la ruptura forma. De este modo, la escritura femenina - siempre más allá de la lógica económica del sistema de equivalencias- se convierte en un proceso infinito, que no puede quedar detenido en una posición, una tesis, un sentido o una verdad; es una producción (y no una expresión), que destruye la hegemonía del discurso falo-logo/céntrico, con el ritmo y el movimiento incansable que imprime un cuerpo histérico, fragmentado por el dolor y el goce. En definitiva, la escritura femenina es un asunto de devenir: una danza que, según dice Anne Berger (2008), consiste en configurar y desconfigurar espacios y lugares, a través del movimiento; en dar un paso dentro, fuera y a un lado, trazando y retrazando los pasos, según un ritmo que difiere de los modos diarios de procesión, en donde se dibuja una nueva manera de vivir (y escribir) el cuerpo.

\section{Las luchas políticas del cuerpo}

Históricamente, la mujer ha sido concebida exclusivamente como un ser enfermo. Desde el discurso científico-médico, la histeria sirve para descalificar el cuerpo femenino, cuya irreverencia pulsional resulta intolerable para la moral burguesa del sistema capitalista. El psicoanálisis lacaniano, si bien desprestigia el cuerpo femenino - siempre la mirada masculina sobre el cuerpo femenino en falta- su teoría va a suscitar mucho interés en los círculos feministas franceses de los años 70.

Reapropiándose de esa posición de 'no-toda', desde el afuera del sistema falologo/céntrico, la escritura femenina de Hélène Cixous va a recurrir al goce suplementario teorizado por Lacan, para demostrar la violencia que ejerce el discurso masculino y deconstruir su posición hegemónica. En contra de la ley de la castración simbólica impuesta por el Nombre-del-Padre, suspendida en los abismos de ese goce suplementario, la escritura femenina rechaza la seguridad que proporciona el proceso teleológico del lenguaje, al dejar que el discurso acoja -en sí mismo- aquello que lo rompe y lo desintegra. Ahora, la destrucción del signo lingüístico abre un espacio ritmado, que inaugura un movimiento (¿una danza?) errática del signo, para poder conservar el goce femenino del cuerpo histérico en la palabra y el silencio: "Hay algo que siempre canta 'detrás' de las palabras", decía Irigaray, "como el rastro de la resistencia de otro irreductible a mí, y que pide practicar incesantemente la apertura entre los signos. Dejando aparecer la carne entre el signo y el signo" (2010: 199). Al matar al padre y destruir la potestad del significante fálico, la escritura femenina - rebelde, crítica e inconformista - permite cuestionar la lógica económica del sistema falologo/céntrico, a través de la desarticulación progresiva del lenguaje discursivo. La destrucción de la equivalencia lingüística - producto de la histerización de la palabra- posibilita la creación de un texto de goce marcadamente político que, 
alejado de las constricciones de la lógica discursiva, se mantiene en el exceso aneconómico que destruye la estabilidad homeostática del sistema de pensamiento dominante. Por eso, la teatralidad del cuerpo histérico se convierte en una nueva posibilidad para el cuerpo y la palabra, ya que la violencia que emerge de la dimensión de lo real-pulsional permite cuestionar los marcos de referencia establecidos por la ciencia médica y la psiquiatría, cuya finalidad —en consonancia con la lógica económica del sistema capitalista- es garantizar el mantenimiento de la estructura social, patologizando el cuerpo femenino (y lleno de goce) de la mujer histérica.

\section{REFERENCIAS BIBLIOGRÁFICAS}

Assoun, Paul-Laurent (1997), Corps et symptôme. Tome 1: Clinique du corps; Tome 2: Corps et inconscient, París, Anthropos.

Berger, Anne (2008), "Sexuar las diferencias”, Lectora, 14: 173-187.

Butler, Judith (1993) Bodies that Matter, Nueva York, Routledge.

Blanchot, Maurice, (1969), L'Entretien infini, París, Éditions Gallimard, 2006.

Brown, Norman (2007), Eros y Tánatos: el sentido psicoanalítico de la historia, Barcelona, Ediciones de Belloch. [1959]

Cixous, Hélène (1986), "La Venue à l'Écriture”, Entre l'Écriture, París, Des femmes: 7-70. [1976]

-(1994), Hélène Cixous, photos de racines, París, Des femmes.

-(2003), L'Amour du loup et autres remords, París, Éditions Galilée.

-(2010a), "Le Rire de la Méduse", Le Rire de la Méduse et autres ironies, París, Éditions Galilée: 35-67. [1975]

-(2010b), "Sorties", Le Rire de la Méduse et autres ironies, París, Éditions Galilée: 68-197. [1975]

Collin, Françoise (2006), Praxis de la diferencia. Liberación y libertad, Barcelona, Editorial Icaria.

Freud, Sigmund (1979), "La interpretación de los sueños", Obras completas IV. La interpretación de los sueños, Buenos Aires, Amorrortu Editores: 1-613. [1900]

-(2008): "Tres ensayos sobre teoría sexual", Tres ensayos sobre teoría sexual y otros escritos, Madrid, Alianza Editorial: 7-114. [1905]

-(2003): "La organización genital infantil (una interpretación en la teoría de la sexualidad", Obras completas XIX. El yo y el ello y otras obras (1923-1925), Buenos Aires, Amorrortu Editores: 141-149. [1923]

—(1979), “¿Pueden los legos ejercer el psicoanálisis? Diálogos con un juez imparcial”, Obras completas XX. Presentación autobiográfica, inhibición, sintoma y angustia. ¿Pueden los legos ejercer el psicoanálisis?, y otras obras (1925-1926), Buenos Aires, Amorrortu Editores: 165-245. [1926] 
Freud, Sigmund y Breuer, Josef (1985), Obras completas II. Estudios sobre la histeria, Buenos Aires, Amorrortu Editores. [1893-1895]

Irigaray, Luce (2009), Ese sexo que no es uno, Madrid, Ediciones Akal. [1977]

-(2010), Ética de la diferencia sexual, Pontevedra, Ellago Ediciones. [1984]

Lacan, Jacques (1999), Encore, París, Éditions du Seuil. [1972-1973]

Michelet, Jules (2009), La bruja. Un estudio de las supersticiones en la Edad Media, Madrid, Ediciones Akal. [1987]

Miller, Jacques-Alain (2008), El partenaire-síntoma, Buenos Aires, Ediciones Paidós.

Roudinesco, Élisabeth (1993), Jacques Lacan: esquisse d'une vie, histoire d'un système de pensée, París, Librairie Arthème Fayard.

-(1994a), Histoire de la Psychanalyse en France I (1885-1939), París, Librairie Arthème Fayard. [1982]

-(1994b), Histoire de la Psychanalyse en France II (1925-1985), París, Librairie Arthème Fayard. [1986]

Roudinesco, Élisabeth y Plon, Michel (1997), Dictionnaire de la Psychanalyse, París, Librairie Arthème Fayard, 2000.

Segarra, Marta (ed.) (2010), Entrevistas a Hélène Cixous. No escribimos sin cuerpo, Barcelona, Icaria Editorial. 